Rev.Saúde públ., S.Paulo, 25(5): 401-5, 1991

\title{
O papel do município no desenvolvimento de políticas de saúde.
}

\author{
The role of local government in health policties.
}

\section{Sueli Gandolfi Dallari*}

\begin{abstract}
DALLARI, S.G. O papel do Município no desenvolvimento de políticas de saúde. Rev. Saúde públ., S. Paulo, 25: 400-5, 1991. A partir de uma análise das evidências que constatam a predominância do interesse local pela saúde nas diversas fases históricas de organização da vida social e, especialmente, da discussão sobre a eficácia dos direitos sociais declarados em algumas Constituições contemporâneas, procura-se definir a responsabilidade pela garantia do Direito à Saúde. A possibilidade de responsabilização pela garantia dos direitos sociais decorre diretamente da definição legal de tais direitos, exequível na esfera local de governo. Examinando-se a estrutura constitucional brasileira para garantia da saúde como direito de todos, conclui-se que a promoção dessa responsabilidade é facilitada pela enumeração das competências municipais em matéria de saúde que são, pormenorizadamente, discutidas.
\end{abstract}

Descritores: Direito à saúde, legislação. Ética médica. Organização e políticas governamentais.

\section{Responsabilidade pela saúde: conflito histórico}

A mais superficial análise histórica demonstra que a saúde foi, tradicionalmente, objeto de competência local. Mesmo quando, na Idade Média, seu cuidado derivava da obrigação moral de caridade, sob a responsabilidade da Igreja, era a paróquia quem organizava a ajuda aos necessitados. Circunscreviase, assim, naturalmente o âmbito de abrangência da organização "sanitária" local, coincidindo com o paroquial. O renascimento acrescentou o poder secular às organizações de benemerência que, no entanto, não perderam seu caráter local. As revoluções burguesas mesmo quando, por considerações puramente relativas ao crescimento econômico, não implantaram seus ideais sociais, já consideraram a assistência aos necessitados um direito**. Todavia, a industrialização, somada ao triunfo incontestável do ideal liberal, acentuou o papel do Estado na área da saúde onde ele era mais facilmente aceito: no controle de doenças transmissíveis e no saneamento do meio. Generaliza-se, então, o conceito de polícia médica que, gradualmente, passa do controle comu-

* Departamento de Prática de.Saúde Pública da Faculdade de Saúde Pública da Universidade de São Paulo, S. Paulo, SP - Brasil. Centro de Estudos e Pesquisas de Direito Sanitário. Núcleo de Pesquisas em Direito Sanitário da Universidade de São Paulo.

** Neste sentido é muito interessante a leitura dos trabalhos da subcomissão da Assembléia Constituinte Francesa de 1789, presidida por La RochefoucauldLiancourt.

Separatas/Reprints: S.G. Dallari - Av. Dr. Amaldo, 715 01255 - São Paulo, SP - Brasil.

Publicação financiada pela FAPESP. Processo Medicina 90/4602-1. nitário para o controle centralizado. Assim, nos Estados Unidos da América (EUA) o poder de polícia, que nunca foi delegado ao poder central (da União), é exercido principalmente por órgãos nacionais, quer se refira ao poder regulador (baseado no artigo I, seção 8 , cláusula 3 da Constituição, que dá ao Congresso o "poder para regular o comércio com as nações estrangeiras, e com os vários Estados, e com as tribos indígenas"), quer se trate do controle da prestação de serviços de saúde.

Os avanços tecnológicos em saúde, aliados ao crescente custo do sistema que os abriga, respondem, entretanto, sem qualquer dúvida, pelo controle realizado pela esfera central de governo sobre a organização sanitária. E o fato é verdadeiro tanto nos Estados que adotam a forma de organização federal quanto naqueles unitários. Apenas para citar dois exemplos, a França, em 1970, instituiu mediante lei (lei $n^{\circ}$ 70-1318, de 31 de dezembro de 1970), a carta sanitária que busca racionalizar a implantação dos equipamentos públicos e privados, considerando, entre outros fatores, a evolução das técnicas médicas. E nos EUA é grande a participação da esfera federal na prestação de serviços de saúde por meio do sistema de "grant-in-aid", que obriga os Estados interessados na obtenção de fundos a submeterem seus planos - que devem demonstrar a necessidade do serviço a ser implantado - ao órgão federal encarregado do setor ${ }^{11,15,20}$

Do mesmo modo, uma rápida observação histórica evidencia o caráter social da saúde $e^{6,14,19}$ e o direito que lhe é conseqüente. Já Aristóteles afirma: "se acreditamos que os homens, como seres humanos, possuem direitos que the são próprios, eles têm então, um direito absoluto de gozar de boa saúde, o que a sociedade e só ela é capaz de proporcionarlhes" (citado por Wartburg ${ }^{23}$ ).

Entretanto, o direito à saúde, que gera a responsabilidade pela prestação de serviços de promoção, 
proteção, e recuperação da saúde, é de formalização recente. Mesmo após o convencimento geral de que "o desprezo e o desrespeito pelos direitos do homem resultaram em atos bárbaros que ultrajaram a consciência da Humanidade"18, o direito à saúde não foi expressamente reconhecido, senão nos Pactos Internacionais em Direitos Humanos. De fato, o artigo 25 da Declaração Universal dos Direitos Humanos dispõe que "toda pessoa tem direito a um nível de vida adequado que lhe assegure, assim como à sua família, a saúde...." mas, é apenas no Pacto dos Direitos Econômicos, Sociais e Culturais, com caráter obrigatório que, embora aprovado em 1966, entrou em vigor, para os Estados que o ratificaram, somente após 1976, que se afirma o reconhecimento "do direito de toda pessoa ao desfruto do mais alto nível possível de saúde física e mental" (art. 12).

$\mathrm{E}$ o acolhimento constitucional do direito à saúde é, também, igualmente, recente. A Constituição da República Italiana, de 22 de dezembro de 1947, o afirma como "direito fundamental do indivíduo e interesse da coletividade" (art. 32), assim como a Constituição da República da Venezuela, de 23 de janeiro de 1961, o faz no artigo 76: "Todos têm direito à proteção da saúde". Entretanto, o reconhecimento constitucional do direito à saúde como norma de exigência imediata tem-se apoiado, especialmente, nas constituições espanhola (de 1978) e portuguesa (aprovada em 1976 e já revista por mecanismo constitucionalmente previsto (art. 286) em 1982 e 1989).

Por outro lado, a existência de normas que reprimem comportamentos considerados nocivos à saúde ou estimulem aqueles que os favorecem, são encontrados nos mais antigos textos legislativos ${ }^{*}$.

\section{Direitos constitucionais relativos à saúde}

Tomando-se como objetivo definir as reponsabilidade em matéria de saúde, torna-se indispensável o exame da situação constitucional do direito à saúde. É ele, de fato, um direito? gera ele alguma obrigação e, conseqüentemente, a responsabilidade pelo não cumprimento desta?

A doutrina contemporânea é unânime ao afirmar que os direitos sociais - chamados por alguns de direitos humanos de segunda geração - incluem o direito à saúde ${ }^{3,9,17}$. Entretanto, a experiência já demonstrou que a simples afirmação, ainda que constitucional, do direito à saúde não tem gerado, na prática, a sua aplicabilidade. Veja-se o exemplo relativamente recente do "caso Nicanor", na República da Venezuela. A Constituição prevê, no artigo

\footnotetext{
* Uma análise da evolução do direito à saúde poderá ser
} consultada em "O direito à saúde" (Dallari ${ }^{4}$ (1988)).
49, que "os Tribunais garantirão a todo habitante da República o gozo e exercício dos direitos e garantias que a Constituição estabelece" e a saúde, como visto, é um desses direitos (art. 76). Pois bem, em julho de 1985, um jovem camponês solicitou o amparo constitucional por encontrar-se em risco de perder a vida, em razão da falta de condições econômicas para o tratamento, que requeria equipes médicas especializadas. A decisão judicial negou-lhe o recurso de amparo (semelhante ao mandado de segurança, no direito brasileiro), por entender que não existia situação jurídica subjetiva infringida ou violação de normas ou princípios constitucionais.

É impossível, todavia, deixar-se de reconhecer a marcante transformação que afeta o direito no Estado contemporâneo que, em fins do século vinte, tem como função atuar políticas públicas ${ }^{3,13}$. O Direito, então, como instrumento de atuação de políticas, públicas permeia todas as matérias constitucionais, e o Estado, além de intervir na sociedade como produtor do direito e realizador da segurança, passa a desenvolver novas formas de atuação, usando o direito positivo como instrumento de implementação de políticas públicas. Assim, não só quando se pensa nos chamados direitos humanos de terceira geração, tal como o direito à preservação do meio ambiente, é óbvio que sua reivindicação dirija-se ao governo do Estado onde os atentados ao equilíbrio ecológico ocorrem; como também é inegável que, mesmo as liberdades individuais - chamadas direitos de primeira geração - "são protegidas pela autoridade do Estado-árbitro contra os abusos do Estado-poder"*.

Portanto, a Constituição tem, no final do século vinte, o papel de definir o direito que instrumentará as políticas públicas. Assim sendo, assente na mais atual doutrina constitucional, onde não se pode deixar de citar a autoridade de Canotilho², Dworkin ${ }^{5}$, Silva ${ }^{21.22}$, Ferrajoli ${ }^{7}$ e Grau ${ }^{12.13}$, deve-se reconhecer a aplicabilidade de todas as normas constitucionais.

É claro que tratar da responsabilização do Estado em matéria de saúde requer a compreensão do conceito de direito - norma ou conjunto de normas jurídicas, com definição concreta que permita, em última instância, que o Poder Judiciário garanta a eficácia das normas relativas à saúde. Deve-se referir, portanto, à realização efetiva dos resultados buscados pela norma.

Neste ponto sobreleva a importância, tanto da declaração constitucional do direito à saúde quanto dos termos em que ele é definido na própria Constituição que, também, organiza o Estado para dar cumprimento à norma. Assim, a forma de Estado instituindo ou não esferas autônomas de poder político é fundamental à responsabilização em matéria sanitária.

\footnotetext{
*cf. Comparato ${ }^{3}$, p.47.
} 
Importa não se confundir a descentralização, que respeita a distribuição de poder político, com a desconcentração, simples distribuição de funçôes administrativas. É curioso notar que tal confusão, frequiente na literatura administrativa, tem levado à conclusōes de caráter, no mínimo, duvidoso. Pregase a descentralização como mecanismo para alcançar maior coordenação e satisfação das necessidades locais, por meio da delegação de autoridades e recursos para o nível comunitário ${ }^{24} \mathrm{e}$ o que, de fato, se realiza é a desconcentração de algumas atividades administrativas, que passam a ser executadas pelo nível local, sob o controle e de acordo com as prioridades definidas na esfera central do governo ${ }^{10}$.

Não é demais insistir em que, ao se tratar de garantia de direitos, estes devem estar expressos em normas jurídicas. É essa a razão porque a real descentralização - implicando definição de prioridades - deve conter a definição do direito constitucionalmente garantido em normas jurídicas: adequadamente no Plano Municipal de Saúde, aprovado por Lei, também, municipal. Igualmente, a insistência na necessidade da declaração constitucional da saúde como direito, implicando a obrigação do Estado de garanti-la para todas as pessoas, não é supérflua. São essas exigências para a adequada interpretação judicial do direito, uma vez que à autoridade judiciária importa apenas formular juízos de legalidade. Encontra-se, pois, o juiz, vinculado à ponderação dos princípios constitucionais, interpretando a Constituição como totalidade. Assim, a norma que atribui ao município brasileiro a competência para "prestar serviços de atendimento à saúde da população" (art. 30, VII), não pode ser considerada isolada daquela que declara ser "competência comum da União, dos Estados, do Distrito Federal e dos Municípios: ..... cuidar da saúde e assistência pública" (art. 23, II), ou da que afirma ser a saúde "direito de todos e dever do Estado" (art. 196) e todas devem ser interpretadas como tendo "aplicação imediata" (art. $5^{\circ}$, parág. $1^{\mathbf{9}}$ ).

\section{Direito à saúde e distribuição de competên- cias no Brasil}

O final dos anos oitenta do século vinte pode ser caracterizado como uma época que começa a se preocupar com a legislação sanitária e, em muitos casos, com sua revisão. Observa-se um conflito, que não se atém aos limites nacionais, entre a tendência centralizadora da legislação, especialmente quando se considera a complexidade da tecnologia envolvida nos serviços e produtos sanitários, e a afirmação das autonomias locais, especialmente quanto à eficácia social da norma jurídica, isto é, quando o que se busca é, no dizer do professor José Afonso da Silva, "uma efetiva conduta acorde com a-prevista pela norma", referindo-se "ao fato de que a norma é realmente obedecida e aplicada"2!.

No Brasil, a competência para legislar sobre "proteção e defesa da saúde" é concorrente, da União, dos Estados e do Distrito Federal (Constituição Federal, art. 24, XII) e dos Municípios (Constituição Federal, art. 30, II). Isso significa que cabe à União apenas o estabelecimento de normas gerais sobre o assunto (art. 24, parág. $1^{9}$ ). Os Estados, que formam a República Federativa do Brasil (art. $1^{\mathbf{9}}$ ), são competentes para suplementar a legislação posta pela União que, não é demais acentuar, limitar-se-á a estabelecer normas gerais (art. 24, parág. $1^{\circ}$ e $2^{2}$ ). Esse parece ser, aliás, o principal papel reservado aos Estados na estrutura constitucional da saúde no Brasil. E, finalmente, cabe aos Municípios, entidades que formam juntamente com os Estados, no dizer do texto constitucional, a República Federativa do Brasil (art. $1^{\circ}$ ), legislar sobre todos os assuntos de interesse local (art. 30, I).

A constituição vigente abandonou a expressão tradicional "peculiar interesse municipal", que não conseguiu definição satisfatória, substituindo-a pelo interesse local, igualmente de difícil conceituação. É indispensável porém compreender-se o conceito de interesse local, haja vista que o sistema constitucional brasileiro é de emuneração de poderes, que delimita de modo estanque as competências de cada esfera de poder político. Assim, salvo expressa disposição da Lei Magna, como nos casos de competência comum previstos no artigo 23 , cada esfera de poder político detém apenas aquelas competências que the foram manifestamente atribuídas. Acentuase, portanto, a necessidade do correto entendimento do que seja assunto de interesse local quando se quer analisar a competência constitucionalmente municipal.

Durante um século, no Brasil, os Municípios tiveram assegurada sua autonomia em tudo quanto respeitasse ao "seu peculiar interesse" (expressão do art. 68, da Constituição de 1891). E as tentativas de conceituação desse interesse peculiar foram inúmeras. Apenas por volta de 1950 uma definição alcançou relativo respeito, sendo adotada por insignes constitucionalistas de diversas correntes de pensamento, tais como Meirelles ${ }^{16}$, Ferreira Filho ${ }^{8}$ e Sil$\mathrm{va}^{22}$. Trata-se daquela decorrente da lição de Sampaio Dória que, após distinguir o privativo do peculiar conclui: "O entrelaçamento dos interesses dos $\mathrm{Mu}$ nicípios com os interesses dos Estados, e com os interesses da Nação, decorre da natureza mesma das coisas. O que os diferencia é a predominância, e não a exclusividade". Foi o mesmo critério - da predominância do interesse o princípio norteador da repartição de competências na federação brasileira de 1988. Ora, é evidente que o mundo contemporâneo praticamente não apresenta problemas que tenham 
reflexos circunscritos ao nível local, nem que sejam particulares a um Estado-membro (nível regional) ou mesmo que respeitem os limites nacionais.

Em consequiência, pode-se concluir que os assuntos de interesse local devem ser compreendidos como aqueles referentes ao peculiar interesse municipal que, dentro da melhor técnica legislativa, serão definidos estudando-se caso a caso qual o interesse predominante para a fixação da competência do município. Não é outra a lição do mestre de Coimbra, Canotilho" "Sendo os preceitos constitucionais modos de ordenação de uma realidade presente mas com dimensão prospectiva (isto é: dirigida ao futuro) e inserindo-se numa pluralidade de quadros de referência, onde o direito político e a política se relacionam, a eles se exige conformação compatível com a natureza da direção política e uma adaptação concreta do programa constitucional".

Pode-se afirmar, portanto, que o município brasileiro está duplamente titulado para legislar sobre proteção e defesa da saúde. O primeiro título referese à competência para suplementar a legislação federal (limitada a normas gerais) e a estadual no que couber (competência enumerada no artigo constitucional - art. 30, II). O segundo, logicamente prioritário, é relativo à predominância do interesse local pela proteção e defesa da saúde como objeto da competência dos Munícipios descrita no artigo 30, I, da Carta Magna contemporânea: "legislar sobre assuntos de interesse local".

Para fazer da saúde um direito social de todos, cuidando, protegendo, defendendo e atendendo-a, a Constituição reconheceu a relevância pública das ações e serviços de saúde (art. 197), definindo um sistema único (art. 198) cujas atribuições enumeradas são:

I - controlar e fiscalizar procedimentos, produtos e substâncias de interesse para a saúde e participar da produção de medicamentos, equipamentos, imunológicos, hemoderivados e outros insumos;

II - executar as ações de vigilância sanitária e epidemiológica, bem como as de saúde do trabalhador;

III - ordenar a formação de recursos humanos na área de saúde;

IV - participar da formulação da política e da execução das ações de saneamento básico;

$\mathrm{V}$ - incrementar em sua área de atuação o desenvolvimento científico e tecnológico;

VI - fiscalizar e inspecionar alimentos, compreendido o controle de seu teor nutricional, bem como bebidas e água para consumo humano;

VII - participar do controle e físcalização da produção, transporte, guarda e utilização de substâncias e produtos psicoativos, tóxicos e radioativos;

VIII - colaborar na proteção do meio ambiente, nele compreendido o do trabalho (art. 200).
No que tange aos cuidados de saúde, a Constituição promulgada em 1988 definiu, conforme já observado, a competência comum da União, dos Estados, do Distrito Federal e dos Municípios (art. 23, II), devendo ser, o adjetivo comum, nessa expressão, entendido em seu sentido literal (do latim commúnis = pertencente a todos ou a muitos). Não é outra a lição de Silva ${ }^{22}$, que, em primeiro lugar, considera competência "a faculdade juridicamente atribuida a uma entidade, ou a um orgão ou agente do Poder Público para emitir decisões". E analisando a extensão em sua classificação, considera a competência comum, cumulativa ou paralela como expressões sinônimas, significando "a faculdade de legislar ou praticar certos atos, em determinada esfera, juntamente e em pé de igualdade, consistindo, pois, num campo de atuação comum às várias entidades, sem que o exercício de uma venha a excluir a competência de outra, que pode assim ser exercida, acumulativamente".

Trata-se, sem dúvida, de forma mais complexa de repartição de competências na federação, compatível com a hodierna ampliação das funções estatais. É claro que não foi objetivo do constituinte brasileiro multiplicar as ações paralelas por todas as esferas de governo, mas sim, multiplicar a responsabilidade em relação a determinadas matérias. Desse modo, sendo todas as esferas de governo do Estado Federal competentes espera-se que haja cooperação entre elas "tendo em vista o equilíbrio do desenvolvimento e do bern-estar em âmbito nacional" (art. 23, parágrafo único).

Conclui-se, portanto, que a expressão constitucional "competência comum" no que respeita ao artigo 23, II, do texto aprovado em 1988, deve ser compreendida como a capacidade e o direito que têm a União, os Estados, o Distrito Federal e os Municípios de legislar e praticar todos os atos administrativos necessários ao cuidado da saúde, "juntamente e em pé de igualdade".

\section{Garantia constitucional do Direito à Saúde}

Partindo-se da constatação de que de nada adianta afirmar o Direito se esse não for implementado, deve-se concluir que a fixação de competências e responsabilidade em matéria de saúde é indispensável à realização do direito. Tornar claro para o Poder Judiciário as balizas que devem orientar a formulação de juízos exclusivos de legalidade, deve ser a tarefa primordial do legislador, enquanto representante do povo. E, no caso brasileiro, a existência de institutos como o princípio constitucional da autoexecutoriedade das normas definidoras dos direitos e garantias individuais (Constituição Federal, art. 5\%, parág. $1^{\frac{9}{}}$ ) ou do mandado de injunção, recurso contra a falta de norma regulamentadora, apenas (C.F. 
art. 5\%, LXXI)*, reforçam o poder popular. Também, especialmente relacionado à saúde, ações e serviços de relevância pública (C.F. art. 197) ficaram sob o zêlo do Ministério Público (C.F. art. 129, II), aumentando o elenco dos instrumentos postos à disposição do povo para a consecução da saúde como direito de todos.

DALLARI, S.G. [The role of local government in health policies]. Rev. Saúde públ., S. Paulo, 25: 401-5, 1991. Analysing the evidences for local concem with health in the various historical phases of the organization of social life, especially relating to the discussion of the efficacy of the social rights written into some contemporary constitutions, the attempt is made to define the responsibility for the guarantee of the right to health. The possibility of defining the responsability for the guarantee of social rights arises directly from the legal definition of such rights, practicable at the level of local govemment. Thus, after a thorough examination of the Brazilian constitutional organization in search of the guarantee of health for all. it is concluded that the promotion of the said responsibility is greatly favored, since Municipal competence regarding issues related to health are listed and discussed there in detail.

Keyworks: Health rights, legislation. Ethics, medical. Government policies and organization.

\section{Referência Bibliográficas}

1. AltaVILA, J. de. Origem dos direinos dos porys. São Paulo, Melhoramentos, s.d

2. CANOTILHO, J.J.G. Constituigäo dirigemte c vim ulas̆üo do legisludor. Coimbra. Ed. Coimbra. 1982.

3. COMPARATO. F.K. Para viver a democrucia. São Paulo, Brasiliense, 1989.

4. DALLARI, S.G. O direito à saúde. Rev. Saúde públ., S. Paulo, 22: 57-63, 1988.

5. DWORKIN, R. A maller of principle. Cambridge. Harvard University Press. 1985

6. ENGELS. F. A situagão da classe trahalhadora na Inglaterra. São Paulo, Global Ed., 1986.
7: $\quad$ FERRAJOLI, L. Diritio e ragione. Roma, Laterza, 1989.

8. FERREIRA FILHO, M.G. Comentários à Constituiçāo brasileira. Sāo Paulo, Saraiva, 1983.

9. FERREIRA FIL.HO, M.G. A aplicação imediata das normas definidoras de direitos e garantias fundamentais. Rev. PGE, S. Paulo, (29): 35-43, jun. 1988.

10. GONSALEZ-BLOCK, $M$. et al. Health services decentralization in México: formulation, implementation and results of policy. Hhh Pol. Plann., 4 (4): 301-15, 1989.

11. GRAD, F.P. The public health la ${ }^{*}$ manual. 2nd ed. Washington, D.C.. American Public Health Association, 1990.

12. GRAU, E.R. Direilo, conceito e normas jurídicas. São Paulo, Ed. R.T., 1988.

13. GRAU, E.R. Contribuiçāo para a interpretaçāo e a crítica do ordem económica na Constituição de 1988. Sāo Paulo. Revista dos Tribunais, 1990.

14. HIPÓCRATES: The medical works of Hippocrates; a new translation from the original greek made especially for English readers by the collaboration of John Chadwick and W.N. Mann. Springfield, 111 ., Thomas, 1950.

15. LIGNEAU, P. Droit de la protection sanitaire et sociale. Paris, Berger-Levrault, 1980.

16. MEIRELLES, H.L. Direito municipal brasileiro. São Paulo, Revista dos Tribunais, 1977

17. MOURGEON. J. L's droits de l'homme. Paris. P.U.F.. 1981.

18. NACOOES LINIDAS: Decluraça Lniversal des Direinos de Homen. Rio de Janeiro, Instituto Nacional de Estudos Pedagógicos/Instituto Brasileiro de Educação, Ciência e Cultura (Comissäo Nacional da UNESCO), 1952.

19. PARACELSUS. On miner's sickness and other miner's diseases. In: PARACELSUS: four treatises of Theuphrastus von Hohenhein called PARACELSUS. Baltimore, Johns Hopkins Press, 1941. p. 43-126.

20. ROSEN. G. Da polícia médica e medicina social. Rio de Janeiro, Graal. 1980.

21. SILVA, J.A. Aplicabilidade das mormas constitucionais. 2" ed. São Paulo. Ed. R.T., 1982.

22. SILVA, J.A. Curso de direito constitucional positivo. 5* ed. Săo Paulo. Ed. R.T., 1989.

23. WARTBURG, W.P. yon A right to health? In: Le droit à lo santé en tant que droit de l'homme. La Haye. Académie de Droit Internacional, 1978. p. 112.

24. WORLD HEALTH ORGANIZATION. Formulating strategies for healh for all by the year 2000. Geneva. 1980.

Recebido paru publicação em $08 / 01 / 1991$. Rcapresentado em 09/05//991. Aproviudo para publicasāo $\mathrm{cm} / 7105 / 199 \mathrm{I}$

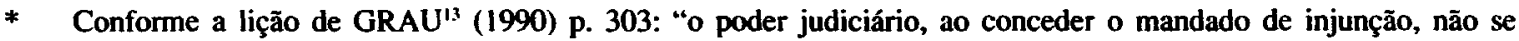
substitui ao Poder Legislativo, não produz norma abstrata e genérica, apenas e tão, somente provê no sentido de viabilizar, dentro das condições que determinar, em cada caso, o exercício dos direitos e liberdades constitucionais e das prerrogativas inerentes à nacionalidade, à soberania e à cidadania. Por isso mesmo é que o mandado de injunção pode ser requerido contra particulares". 